\title{
INVESTIGATION ON SOIL MOISTURE RESERVES AND METEOROLOGICAL CONDITIONS IN RELATION TO BASIC SOIL TYPES IN BULGARIA
}

\author{
Veska Georgieva', Valentin Kazandjiev' ${ }^{1}$, \\ Marek Degórski², Krzysztof Błażejczyk², Magdalena Kuchcik², Bożena Degórska² \\ ${ }^{1}$ National Institute of Meteorology and Hydrology, \\ Bulgarian Academy of Sciences \\ 66 Tsarigradsko shausse, 1784 Sofia, Bulgaria \\ veska.georgieva@meteo.bg, valentin.kazandjiev@meteo.bg \\ 2 Institute of Geography and Spatial Organization, \\ Polish Academy of Sciences, \\ Twarda 51/55, 00-818 Warsaw, Poland \\ m.degor@twarda.pan.pl,k.blaz@twarda.pan.pl,mkuchcik@twarda.pan.pl,bodego@twarda.pan.pl
}

\begin{abstract}
The work described here has sought to determine soil water content change and its relation with the change in the main agro-climate forming meteorological elements for the 1981-2010 period in comparison with the 1951-1980 one. Changes in the main meteorological elements, which lead to spoiled agrometeorological conditions in the second half of the $20^{\text {th }}$ century over the Bulgaria, were identified. These trends are confirmed in the climatic scenarios for future changes through to 2050 and 2070.
\end{abstract}

Keywords: soil water content, agrometeorological conditions, climate change, winter wheat.

\section{Introduction}

Almost all sectors of the economy are affected by climate change, but agriculture experiences its impact directly. Located in the sub-humid zone, Bulgaria is characterised by an insufficient water supply, a limiting factor when it comes to obtaining high yields. As the soil water supply in the rooting zone at crucial phenological stages is the main parameter used in assessing and zoning Bulgaria's land for crop growing (Georgieva et al. 2009, 2010), soil water content in the root-forming zone at such stages is a key parameter in resource assessment.

Measured data on soil water content are available in the database of the NIMH (National Institute of Meteorology and Hydrology), for a period of 60 or more years, as are phenological data for the major agricultural crops. 
Much research on soil water content and associated probabilities has been done, with a view to yield-support actions in Bulgarian agriculture and science being improved. Using datasets for shorter periods in relation to the main soil types, water probabilities were assessed by: Dilkov et al. $(1959,1960)$ - for chernozems, Vangelov $(1963,1965)$ - for cinnamoic soils, Dukov (1976) - for grey soils and Vandova and Serkedjieva (1984) - for vertisols. From 2000 onwards, studies were carried out using longer (30-year) datasets, with trends for the main meteorological elements being examined, to facilitate research into water probability and trends for soil water content as regards various agricultural crops (Slavov \& Georgieva 2005, Slavov et al. 2005). Analysis of the data on soil water content and certain other ecological indicators revealed a deterioration in hydrometeorological conditions over southern Bulgaria, as well as a reduction in soil water capacity in the layer of the top one and a half meters during the entire growing season for winter wheat in south-east Bulgaria (Slavov \& Georgieva 2005). Soil water content is changing at the main stages of phenological development of winter wheat, and seen as an indicator of climate change. Analysis of some of the ecological indicators used simultaneously showed that, in comparison with other parts of the country the Ruse region is not experiencing significant changes in hydrometeorological conditions (Slavov et al. 2005).

Regions favourable or unfavourable for the cultivation of winter wheat under moist conditions, along with trends for soil water capacity in the main soil types were examined by comparing the 1971-2000 and 1961-1990 periods (Georgieva 2014). Studies on trends for long-term variation in soil water content shaped by meteorological elements during the second half of the $20^{\text {th }}$ century show a steadily upward trend for temperature and reductions in, or a changed annual distribution for, rainfall (Alexandrov 2006, Koleva \& Alexandrov 2008). Annual average air temperature increases for the 1971-2000 period in comparison to $1961-1990$ period of $1.5^{\circ} \mathrm{C}$. The increase is greater in northern Bulgaria, while there is no increase in the south of the country (Kazandjiev 2008a, b, Eitzinger et al. 2008, Kazandjiev et al. 2009). As a result, the duration of the period with temperatures above $5^{\circ} \mathrm{C}$ is prolonged (by 6-10 days) in comparison with the 1961-1990 period. Moisture conditions relate directly to the rainfall total. Koleva and Alexandrov (2008) established that a decrease in annual rainfall totals had occurred in the Danubian Plain area and the Thracian Valley, while there had been an increase in the frequency of dry years as compared with the previous century. The annual rainfall total for agricultural land in the north-eastern part of Bulgaria is down by $40 \mathrm{~mm}$ in comparison with that for the 1961-1990 period (Kazandjiev et al. 2011). It should be emphasized that the region of East Dobrudja stands out as an area with the smallest annual rainfall total, though November rainfall in this area is higher than that in remaining parts of the country (Stanev et al. 1991).

The trends described have led to a change in agrometeorological conditions. (Kazandjiev et al. 2009, Georgieva et al. 2007). Using data for the 1971-2010 period, Kazandjiev et al. (2011) found that the average annual temperature in north-eastern Bulgaria had increased thanks to changes in winter temperatures. In turn, analysis of absolute minimum and maximum air temperatures and numbers of days with a temperature over 5 and $10^{\circ} \mathrm{C}$ has shown that the pace of climate change in this region is moderate.

The frequency of occurrence of drought periods, as compared with the current climate of 19611990 is found to be higher during the last 20 years (1991-2010), especially in the Thracian lowland and the north-east of Bulgaria (Alexandrov et al. 2011). According to the index of De Martonne, a moderately moist climate becomes dry, and will not be able to rely on economically effective yields, unless irrigation is resorted to in some areas (Kazandjiev et al. 2014).

The annual assessment of the first decade of the $21^{\text {st }}$ century in Bulgaria reveals some dry and some wet years (WMO 2012). The increased incidence of extreme fluctuations in weather (Bocheva 
2012, Bocheva et al. 2013) encourages investigation of the influence these processes exert on moisture conditions, and ultimately on soil water supply, as a limiting factor where the productivity of plants is concerned.

Analysis of climate scenarios, generating data for 2050 and 2070 as regards the main meteorological elements, also sustains the idea that meteorological conditions will tend to worsen to the end of this century.

The specific objective of the work detailed in this paper has been to determine changes in soil water content, and the latter's relationship with changes in the main agro-climate forming meteorological elements for the 1981-2010 period, in comparison with those for the 1951-1980 period.

\section{Materials and methods}

It was monthly rainfall data, mean monthly air temperature and soil moisture measurement data from the NIMH's database that were processed. The observations within the agrometeorological network started in 1951. There are 28 points now. Such measurements allow for the comparison of two thirty-year periods: 1951-1980 and 1981-2010, at seven stations. The data from Knezha, Novachene, Pavlikeni, Tsarev Brod, General Toshevo, Karnobat and Chirpan are analyzed (Fig. 1). These stations are located on agricultural land, at altitudes below $800 \mathrm{~m}$. They are representative for the two soil types of chernozems and vertisols. They are situated in the European continental climatic region, albeit in two climatic sub-regions that are: temperate-continental (Knezha, Novachene, Pavlikeni, Tsarev Brod and General Toshevo) and transitional-continental (Karnobat and Chirpan).

The soil water measurements in the agrometeorological network are made using the gravimetric method at 10-day intervals, at depths of $10 \mathrm{~cm}$ up to $1 \mathrm{~m}$, as well as once a month in winter. Twice a year, soil water content is measured at up to $2 \mathrm{~m}$ depth, with measurements from 1 to $2 \mathrm{~m}$ made every $20 \mathrm{~cm}$. The data used are for land under winter wheat. Stations represent chernozems and vertisols. Water supply at the wilting point in the $1 \mathrm{~m}$ soil layer varied between 137 and $207 \mathrm{~mm}$, which is 45 to $56 \%$ of field capacity (FC) for chernozems (Tab. 1). Field capacity (FC) is $350 \mathrm{~mm}$, and the available water supply (AWS) varied between 115 and $168 \mathrm{~mm}$. For Vertisols, water supply at wilting point is $250 \mathrm{~mm}$ (61\% of FC). Field capacity supply is $450 \mathrm{~mm}$ and AWS $160 \mathrm{~mm}$.

The homogeneity of the means obtained is assessed using one-way analysis of variance. As a null hypothesis, we accepted that there are no statistically significant differences between the two data series. Trends for soil water content changes are assessed using the nonparametric Mann-Kendall test. With this we tested the null hypothesis of no trend $H_{o}$, against the alternative hypothesis $H_{l}$, in which there is an upward or downward monotonic trend. Use was made of $S$-statistics and the normal approximation ( $Z$ statistics). The condition for an upward trend is if $Z>0$ and vice versa. To test for either an upward or downward monotone trend, a two-tailed test was used at tested significance levels of $\alpha=0.001, \alpha=0.01, \alpha=0.05$ and $\alpha=0.1$. 


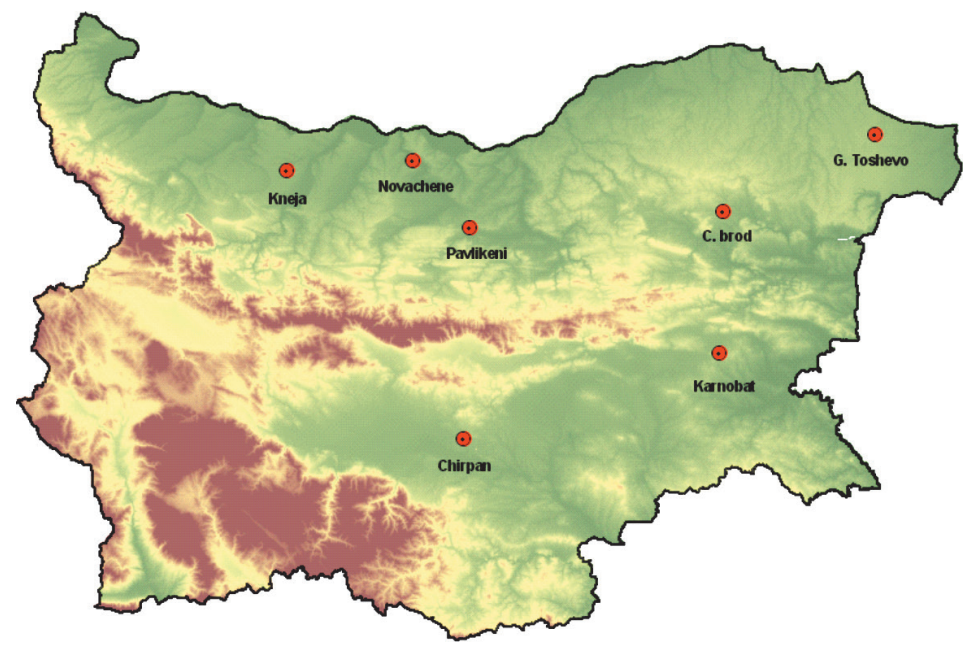

Figure 1. Spatial locations of agrometeorological stations made use of in the Bulgarian study

Table 1. Moisture and physical properties of different basic soil types

\begin{tabular}{|l|c|c|c|c|}
\hline \multicolumn{1}{|c|}{ Soil } & $\begin{array}{c}\text { Water supply } \\
\text { at wilting point } \mathbf{( m m )}\end{array}$ & $\begin{array}{c}\text { Water supply at field } \\
\text { capacity (mm) }\end{array}$ & $\begin{array}{c}\text { Available water } \\
\text { supply (mm) }\end{array}$ & $\begin{array}{c}\text { WP as \% } \\
\text { of FC }\end{array}$ \\
\hline 1. Typical chernozems & 180 & 336 & 157 & 53 \\
\hline 2. Calcareous chernozems & 137 & 305 & 168 & 45 \\
\hline 3. Leached chernozems & 207 & 371 & 115 & 56 \\
\hline 4. Leached vertisols & 250 & 408 & 158 & 61 \\
\hline 5. Typical vertisols & 286 & 471 & 185 & 61 \\
\hline
\end{tabular}

One relatively simple way to characterize the thermal conditions for a given month or season is to compare the sums for active temperatures during the survey period with those of a reference period. In our case we calculate the active temperatures by months from April to October for the period 1981-2010 and compare them with the values in the period 1951-1980. Furthermore, we have used comparisons of De Martone aridity index (IDM) values, as are used for comprehensive assessments of meteorological conditions.

The index is calculated as $I_{D M}=\frac{12\left(\sum P\right)}{T+10}$ (De Martone 1925), where: $P$ is monthly precipitation in $\mathrm{mm}$ and $T$ is the monthly mean air temperature in ${ }^{\circ} \mathrm{C}$.

\section{Results and discussion}

Monthly average values for soil water supplies were analyzed for the $0-20 \mathrm{~cm}, 0-50 \mathrm{~cm}$ and $0-100 \mathrm{~cm}$ soil layers, over the periods 1951-1980 and 1981-2010. At the Knezha, Novachene and Chirpan stations, the differences in monthly values across all the examined soil layers were negative. In the case of Pavlikeni there was one positive difference, relating to October (Fig. 2).

Reductions in soil water supply equal to 14,13 , and $11 \%$ of FC respectively were reported for the $0-20 \mathrm{~cm}, 0-50 \mathrm{~cm}$ and $0-100 \mathrm{~cm}$ layers at Knezha, in the month of May (Fig. 2). The ranges of the 
deviations in soil water content correspond with deviations in rainfall totals, except in the case of June. The negative deviation in soil moisture content, which does not match with those for rainfall in June, may be due to reduced water consumption in plants, due to their early entry into wax stages and full maturity in the second period, as established by earlier research from our team (Kazandjiev et al. 2009).
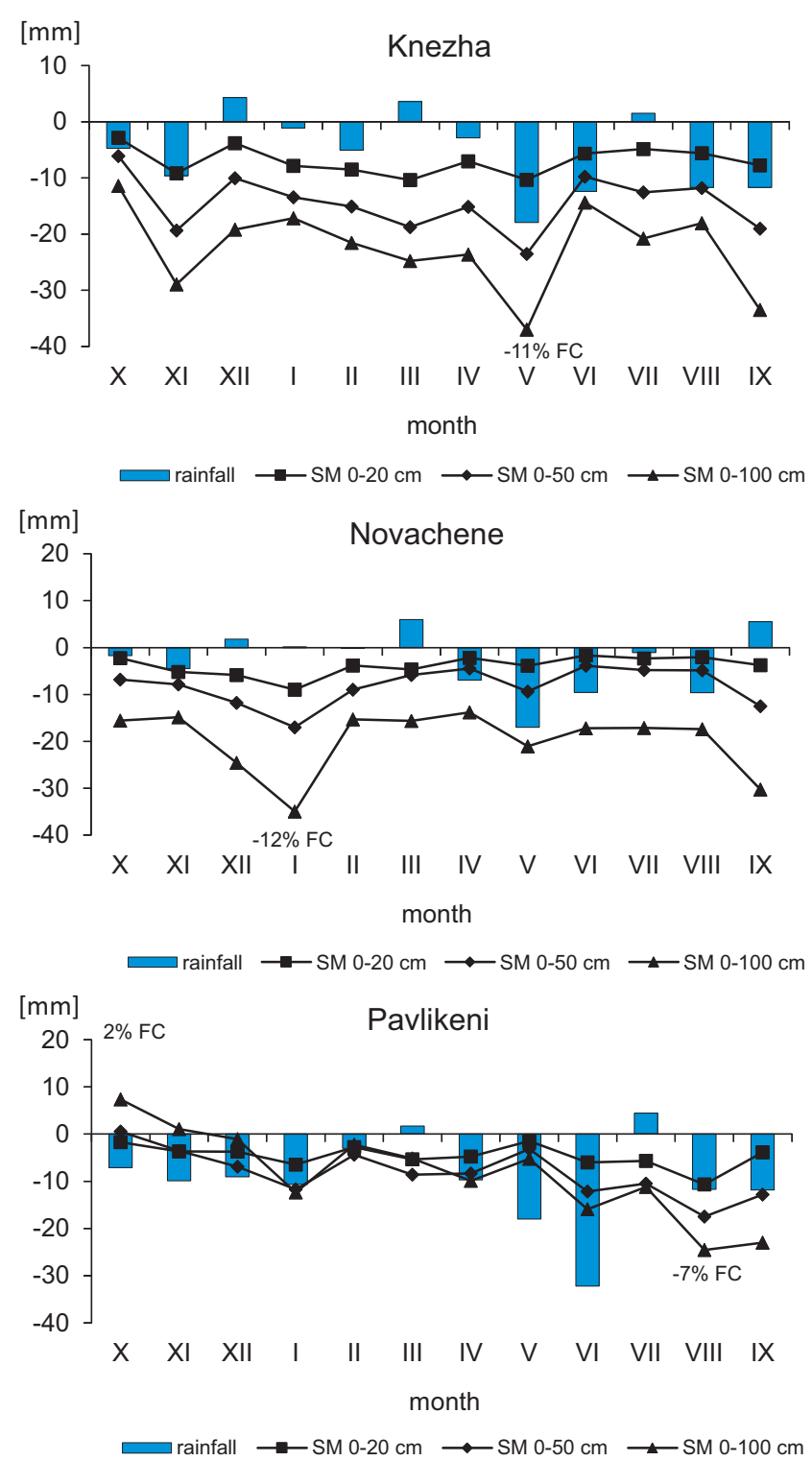

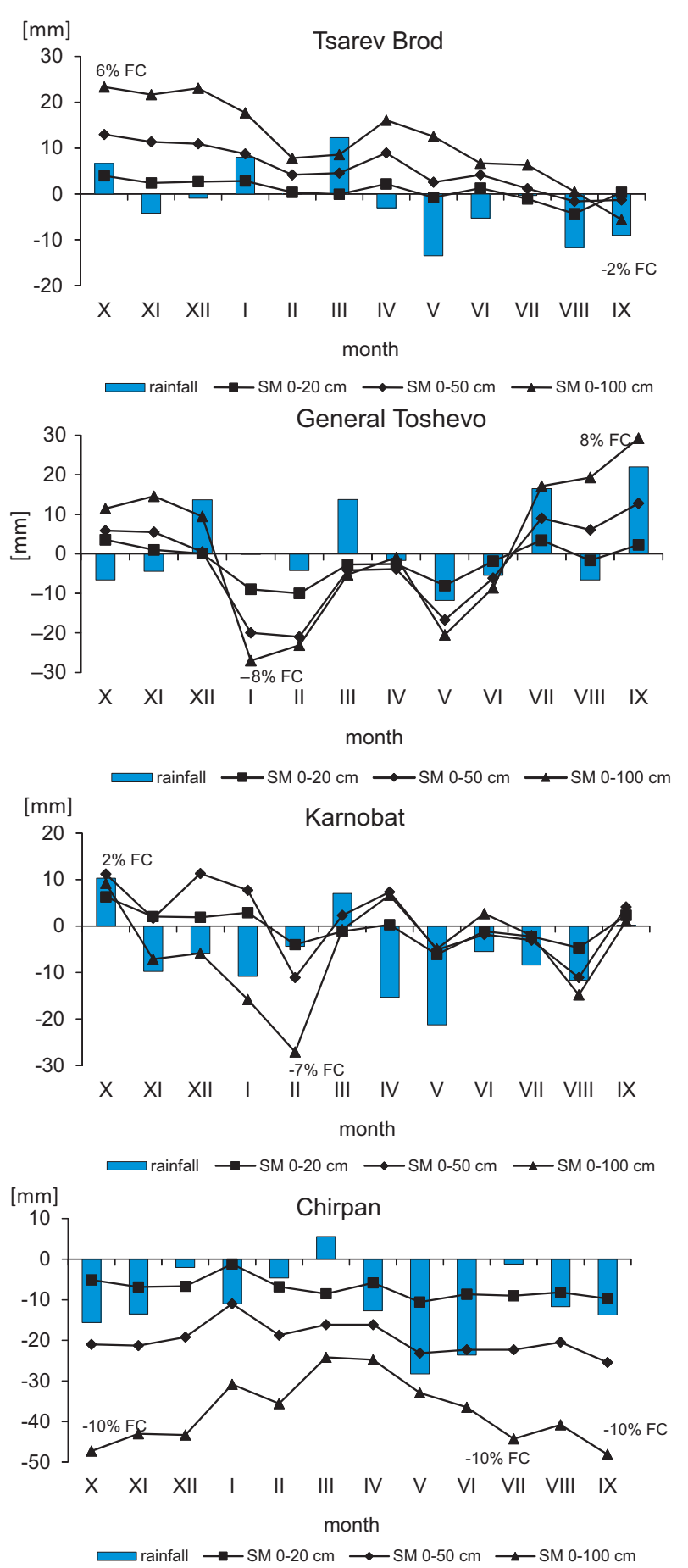

Figure 2. Differences $(\mathrm{mm})$ in monthly average soil moisture supply in the 0-20, 0-50 and 0-100 cm soil layers (SM), as well as rainfall totals (r) for the periods 1981-2010 and 1951-1980 
A Student's T-test was used to determine the homogeneity of average monthly values for soil water reserves (Tab. 2) for the two periods. This reveals statistically significant differences for all months except July and October, for the three soil layers, and in August for the 0-100 cm layer. Statistically significant differences in average monthly rainfall were not observed in the case of any months (Tab. 3).

At the beginning of the growing season, soil water levels in the three soil layers show a statistically significant reduction during the second period. This is related to an average monthly air temperature that is higher by $1^{\circ} \mathrm{C}$ in the cases of October and December, as well as a reduction of monthly rainfall equal to $10 \mathrm{~mm}$. Decreases in rainfall totals in April and May, combined with an increase in active temperatures of $10-20$ up to $30-35^{\circ} \mathrm{C}$ (Fig. 3.) causes a maximal reduction in the soil water supply. This coincides with the period of greatest water consumption by plants and is in direct relation with yield. The comprehensive assessment of the meteorological conditions in Knezha during the growing season is made by applying the De Martone Aridity Index $\left(\mathrm{I}_{(\mathrm{DM})}\right)$. During the second period, the conditions were unfavourable and water consumption increased by $9 \mathrm{~mm} /{ }^{\circ} \mathrm{C}$ in the case of May and $6 \mathrm{~mm} /{ }^{\circ} \mathrm{C}$ in June, remaining unchanged in July. August is characterized as dry sub-humid (Fig. 4).

In the case of all of the years studied, a decrease in soil water supply is established for Novachene. In winter, supplies are lower by 14,11 and $12 \%$ of $\mathrm{FC}$ in the $0-20,0-50$ and $-100 \mathrm{~cm}$ layers respectively where January is concerned (Fig. 2), in the circumstances of a minor reduction in rainfall totals, but an increase in average daily temperature equal to $1.5^{\circ} \mathrm{C}$ (Fig. 3). A reduction of $8 \%$ from $\mathrm{FC}$ in the $1 \mathrm{~m}$ top layer is observed in May as a result of a reduction (of $17 \mathrm{~mm}$ ) in the rainfall total. There are differences in soil water supply in December for the 0-20 and 0-50 cm soil layers. In March in the case of all the described layers, and in September in the deeper soil layers of 0-50 and 0-100 cm, the differences achieve statistical significance (Tab. 2). In the cases of the average monthly rainfall totals for the two periods, there are no statistically significant differences (Tab. 3). The conditions as regards humidity during the growing season are worse in the second (1981-2010) period. In April and May, $\mathrm{I}_{\mathrm{dm}}$ decreases, but remains within typical for the moist sub-humid zone, while in June, July and August the De Martonne aridity index passes below $20 \mathrm{~mm} /{ }^{\circ} \mathrm{C}$, which characterizes conditions as dry sub-humid (Fig. 4).

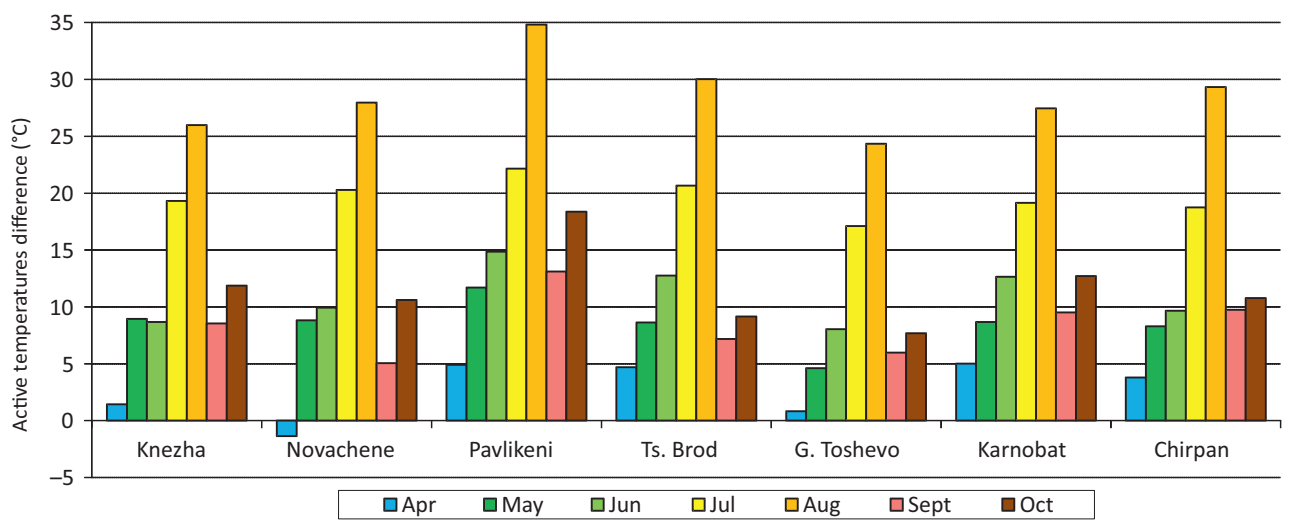

Figure 3. Deviation of active temperature totals by months of the growing season for the period 1981-2010 in comparison with 1951-1980 

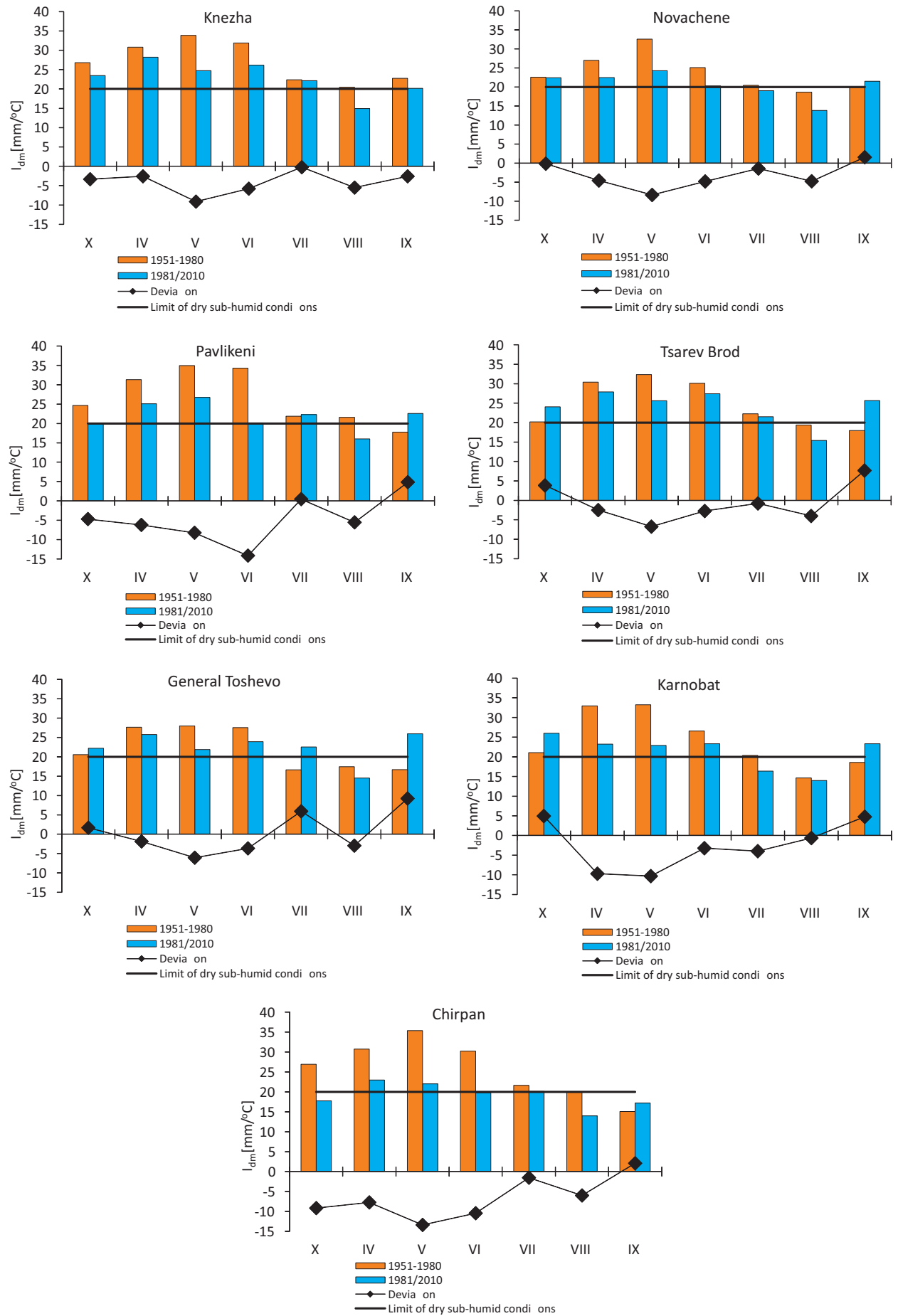

Figure 4. De Martone aridity index for the growing season in the periods 1951-1980 and 1981-2010, with deviations for the latter period as compared with the former 
Due to the greater water capacity of the vertisols near Chirpan, the reduction in soil water content is greater in terms of absolute values: at 48,47 and $44 \mathrm{~mm}$, in the top $1 \mathrm{~m}$ soil layer in September, October and July respectively, with this corresponding to $10 \%$ of FC (Fig. 2). Analysis of homogeneity of the average soil moisture showed a statistically significant reduction in the second (1981-2010) period, compared with 1951-1980, in the case of most months of the year and for all layers. Exceptions concern May, July and September in regard to all three soil layers, and October in the case of the 0-20 cm layer (Tab. 2).

The largest reductions in monthly rainfall totals are reported in May and June, reaching 28 and $24 \mathrm{~mm}$ respectively (Fig. 2). We established the existence of statistically significant reductions for the second period as compared with the first (Tab. 3). The same trends are to be observed for the annual rainfall total. Values of $\mathrm{I}_{\mathrm{dm}}$ are lower during the growing season in April and May only, though they remain in the group characteristic for a moist sub-humid climate (Fig. 4).

The soil water supply for Pavlikeni in October and November is positive in the case of the top $1 \mathrm{~m}$ layer: the increase is of up to $2 \%$ from FC. In other months, it is decreased by $7 \%$ from FC (in August). In the other two soil layers, decreasing reduction in soil water probability is to be observed in all months, though the highest values are those for June ( 9 and 6\% down from FC) and August (13 and $7 \%$ from FC). There is a statistically significant reduction in the second period in March, June and August for the 0-20 and 0-50 cm layers, and in December for the 0-20 cm layer only (Tab. 2). In June we observed the largest (statistically significant) reduction in the amount of rainfall, which was equal to $32 \mathrm{~mm}$ (Tab. 3). Humidity conditions during the winter-wheat growing season are less favourable during the second period. In October, June and August, values of $\mathrm{I}_{\mathrm{dm}}$ are reduced below $20 \mathrm{~mm} /{ }^{\circ} \mathrm{C}$ and are therefore capable of being characterized as dry sub-humid (Fig. 4).

The deviations of soil water content for the other three stations have a different sign. In General Toshevo, deviations range from an increase of 5\% in FC in October and July for the $0-20 \mathrm{~cm}$ layer to 7 and $8 \%$ of FC in September, respectively for the $0-50$ and $0-100 \mathrm{~cm}$ layers; as well as decrease by $14 \%$ of FC in February in the $0-20 \mathrm{~cm}$ layer, by $11 \%$ of FC in January and February in the $0-50 \mathrm{~cm}$ layer and by $8 \%$ of FC in January in the case of the top $1 \mathrm{~m}$ soil layer (Fig. 2). The reduction in soil water content during the winter months is related to the increase in average monthly air temperature, of $1^{\circ} \mathrm{C}$ in January and $1.2^{\circ} \mathrm{C}$ in February. There are no significant changes in soil water content, but we established that the average values for precipitation show a statistically significant increase in the rainfall total in September (Tab. 2 and 3). Assessment of the humidity conditions at the General Toshevo station shows an improvement in July and September when rainfall continues to increase by 17 and $22 \mathrm{~mm}$ (Fig. 2 and 4). In July, conditions improve from dry sub-humid to moist sub-humid. Only in August due conditions continue to qualify for the dry sub-humid designation.

In the two shallow layers $(0-20$ and $0-50 \mathrm{~cm})$ at the Karnobat station, soil water content in the second thirty-year period is characterized by positive deviations from October through to January, in circumstances of negative deviations of rainfall that reach 8 and 5\% of FC, respectively. In February negative deviations were observed for these two layers. During the growing season in March and April, they are positive, however, and after that the soil water content for the second period is lower than that in the first. For the top $1 \mathrm{~m}$ soil layer, the deviations are positive in October ( $2 \%$ of FC), April and September (1\% of FC). For the rest of the time, they are negative, reaching $7 \%$ of FC in February. There are no statistically significant changes in the average values for soil water content, but the amounts of rainfall during the second (1981-2010) period are significantly lower than those in the first (Tab. 2, 3). Because of soil-profile specifics, the reduction affects the deeper soil layers during May, when in all three soil layers the soil water content during the second period is lower than 
during the first. The comprehensive assessment of humidity conditions indicates an improvement in September and October (Fig. 4). Despite the reduction of $I_{d m}$ in the case of the growing season for winter wheat, the region of Karnobat remains an area categorizable as having a moist sub-humid climate.

Only at the Tsarev Brod station did soil water content show a predominant increase during almost all months of the year, in the case of all three soil layers. The most major increases, reaching 6,8 and $7 \%$ of FC in October, in the case of the three soil layers respectively, are those registered in winter. In April, there is also an increase in soil moisture, probably due to the increase in amounts of rainfall in March. Decreases of 6,1 and 2\% of FC respectively are observed in August and September (Fig. 2), though these changes do not achieve statistical significance (Tab. 2, 3). Humidity conditions improve in September and October, and, notwithstanding the aggravating of conditions in remaining months, the growth period for wheat - in April, May and June - sees them remain within the limits characteristic for a moist sub-humid climate (Fig. 4).

Table 2. Statistical significance of average difference in soil-water reserves for different soil layers and for both the 1951-1980 and 1981-2010 periods

\begin{tabular}{|c|c|c|c|c|c|c|c|c|c|c|c|c|}
\hline \multirow{2}{*}{ Stations } & \multirow{2}{*}{ Soil layer } & \multicolumn{11}{|c|}{ Month } \\
\hline & & $\mathbf{X}$ & XI & XII & II & III & IV & V & VI & VII & VIII & IX \\
\hline \multirow{3}{*}{ Knezha } & $0-20 \mathrm{~cm}$ & & $*$ & * & $*$ & * & $*$ & $*$ & $*$ & & $*$ & $*$ \\
\hline & $0-50 \mathrm{~cm}$ & & $*$ & $*$ & $*$ & $*$ & $*$ & $*$ & $*$ & & $*$ & $*$ \\
\hline & $0-100 \mathrm{~cm}$ & & $*$ & * & $*$ & $*$ & * & $*$ & $*$ & & & $*$ \\
\hline \multirow{3}{*}{ Novachene } & $0-20 \mathrm{~cm}$ & & & $*$ & & $*$ & & & & & & \\
\hline & $0-50 \mathrm{~cm}$ & & & $*$ & & $*$ & & & & & & $*$ \\
\hline & $0-100 \mathrm{~cm}$ & & & & & $*$ & & & & & & $*$ \\
\hline \multirow{3}{*}{ Pavlikeni } & $0-20 \mathrm{~cm}$ & & & * & & $*$ & & & $*$ & & * & \\
\hline & $0-50 \mathrm{~cm}$ & & & & & $*$ & & & $*$ & & $*$ & \\
\hline & $0-100 \mathrm{~cm}$ & & & & & & & & & & & \\
\hline \multirow{3}{*}{ Chirpan } & $0-20 \mathrm{~cm}$ & & $*$ & $*$ & $*$ & $*$ & $*$ & & $*$ & & $*$ & \\
\hline & $0-50 \mathrm{~cm}$ & $*$ & $*$ & $*$ & $*$ & $*$ & $*$ & & $*$ & & $*$ & \\
\hline & $0-100 \mathrm{~cm}$ & $*$ & $*$ & $*$ & $*$ & $*$ & $*$ & & $*$ & & $*$ & \\
\hline
\end{tabular}

Table 3. Statistical significance of average differences in rainfall totals for the both 1951-1980 and 1981-2010 periods

\begin{tabular}{|l|c|c|c|c|c|c|c|}
\hline \multirow{2}{*}{\multicolumn{1}{c|}{ Stations }} & \multicolumn{7}{c|}{ Month } \\
\cline { 2 - 8 } & IV & V & VI & VII & VIII & IX & ANNUAL \\
\hline Pavlikeni & & & $*$ & & & & $*$ \\
\hline G. Toshevo & & & & & & $*$ & \\
\hline Karnobat & $*$ & $*$ & & & & & \\
\hline Chirpan & & $*$ & $*$ & & & & $*$ \\
\hline
\end{tabular}

Other than at the Tsarev Brod station, a decrease in soil-water supplies is observed during the autumn-winter period, when the soils are saturated. At Novachene, General Toshevo and Pavlikeni, the peak decrease is that noted for January, reaching, respectively for the three layers: 14, 11 and 
$12 \%$ at Novachene, 12, 11 and $8 \%$ of FC at General Toshevo; and 8, 6 and 3\% of FC at Pavlikeni. At Karnobat, the reduction reaches $5 \%$ of FC in both shallow layers and $7 \%$ of FC in the $0-100 \mathrm{~cm}$ layer. The most marked reductions are: at Chirpan in October $(5,9$ and 10\% of FC) and in Knezha in November $(12,11$ and $9 \%$ of FC). These results show an intensification of a trend identified by previous studies of our team in the case of an earlier period (Georgieva 2014). At the beginning of spring vegetation, soils have not reached full saturation in the $1 \mathrm{~m}$ soil layer. Only at Tsarev Brod during the winter period is there an increase of 6,8 and $7 \%$ of FC respectively, in the three soil layers.

During spring vegetation, substantial and statistically significant negative deviations are to be observed in Knezha, reaching 14, 13 and $11 \%$ of FC respectively, in the three soil layers. In May at General Toshevo negative deviations of 11,9 and $6 \%$ of FC are to be observed, though the decrease does not achieve statistical significance. What is significant is the decrease in soil water supply in June in the shallow $(0-20$ and 0-50 cm) soil layers that reach 6 and $4 \%$ of FC in Pavlikeni. In Chirpan in April and June, the decrease in the case of all three soil layers is of between 6 and $10 \%$ of FC. The decrease in May reported in Novachene is of $6-7 \%$ of FC, but this is not statistically significant. Upward trends are only to be noted at Tsarev Brod and Karnobat except in May, reaching 5 and 4\% FC.

During the months of April, May and June at all stations, it was possible to observe relatively small differences in active temperatures between the period of investigation and the reference period (1951-1980). The differences increase sharply increasing in July and August, however, reaching 20-30 ${ }^{\circ} \mathrm{C}$ (in Knezha, Novachene, Tsarev Brod, G. Toshevo and Chirpan) and more in Pavlikeni, remaining comparatively higher to the end of the growing season - the months of September and October. This is precognition for evaporation and evapotranspiration rise, which supposes fast depletion of soil water reserves and an increasing number of irrigations and increasing amount of water for compensation.

The locations of points with a year-round reduction in the three soil layers are in the central part of the Danubian Plain and the Thracian Valley, and at Tsarev Brod, a station with an year-round increase in soil water supply, which is located in north-eastern Bulgaria. These results confirm the data the team obtained in previous studies for an earlier period (Kazandjiev et al. 2009). According to those data, the main resource determining the level of soil water content - precipitation manifests different trends when it comes to change in climate during the 1971-2000 period as compared with the 1961-1990 period. The eastern part of Bulgaria (Ruse - M. Tarnovo) is characterized by upward trends for precipitation. In the rest of the country, the trend is downward.

How do changes in soil water supplies affect the growth, development and yield of the winter crop? The water for sowing and germination is provided by the $20 \mathrm{~cm}$ soil layer whose supplies in September and October are crucial. Only in Knezha in September did we observe a statistically significant reduction in soil water content (like at Chirpan in October, when $\mathrm{I}_{\mathrm{dm}}$ falls below $20 \mathrm{~mm} /{ }^{\circ} \mathrm{C}$ ). In Tsarev Brod, from unfavourable conditions of humidity during the first period, when values may be under $\mathrm{I}_{\mathrm{dm}} 20 \mathrm{~mm} /{ }^{\circ} \mathrm{C}$, we move in the second period to values that place the area within the zone of a moist sub-humid climate.

As water accumulation proceeds in winter, we observe the most significant negative changes in water supplies. Nevertheless, the trends for changes in precipitation do not achieve statistical significance, with a complex of factors determining quantities of soil water that are changed. The increase in temperature in the second period and the temperature fluctuations characterizing the transitional months, as well as winter, leads to consumption of water by evaporation and long warming periods and also transpiration. The transitions through $5^{\circ} \mathrm{C}$ are taking place at an earlier date in the spring and a later date in the autumn, with this leading to a shift in phenological stages. 
In the spring growing season for all points of investigation except the Tsarev Brod station, soil water supplies in the $1 \mathrm{~m}$ soil layer are shown to be decreasing. The greatest impact on productivity is that exerted by the negative deviation in May, when the ear-formation phase occurs in most areas of the country.

Fixed and assessed are the trends for change in soil water supplies and the rainfall total for the 1981-2010 period (Tab. 4, 5). Statistically significant trends for change in soil water content at the Tsarev Brod and General Toshevo stations are not observed. Proven with high levels of significance are trends towards a reduction in soil water supplies in Knezha and Novachene, for all three considered soil layers, in March. In Karnobat and Chirpan, downward trends are also found, but with a significance level of 0.05 and 0.1. There are no significant trends for Pavlikeni. In the deeper soil layers in Knezha, Chirpan and Novachene a negative trend for soil water content is present in April. The same tendencies are observed in May in Knezha and Novachene. In Knezha in June, although with less significance, the soil water supplies are decreasing, as they are in Chirpan, in the three soil layers and especially the $0-50 \mathrm{~cm}$ layer, where the downward trends achieves its greatest significance (0.001). In August it is only in Pavlikeni and Chirpan that it was possible to report negative trends.

Trends for soil water content relate to deterioration in humidity conditions at certain stages of phenological development of winter wheat. The downward trends for soil water supplies in September and October in Karnobat, Chirpan, Knezha and Novachene make t pre-sowing tillage difficult. This trendy leads to delay in emergency or irregularity of the process, which is risky for the dormancy. A downward trend for soil water content at the start of the spring vegetation period is observed at all stations except Tsarev Brod and General Toshevo, where the one-meter soil lis not fulfilled to FC. This increases the risk of drought if consecutive days without rain appear during the growing season.

Except in a very few cases, downward trends for rainfall compared with trends for soil water are contrary ones. The only upward trend is for rainfall observed at General Toshevo in September, at level of significance equal to 0.01 . Achieving the same level of significance are trends for decreased precipitation in Chirpan in November, May and June. A statistically significant downward trend is also to be observed in the case of soil water content in May. This could be the result of heavier mechanical composition and greater water capacity of the vertisols. In June, however these also display a trend towards reduction in Karnobat. 
Table 4. Normal approximation (Z) and level of significance (L.S.) of soil water supply by soil layers (0-20 cm, 0-50 cm and 0-100 cm) during the period $1951-2010$

\begin{tabular}{|c|c|c|c|c|c|c|c|c|c|c|c|c|c|c|c|c|c|c|c|c|c|c|c|}
\hline \multirow{2}{*}{ Station } & \multirow{2}{*}{ Soil layer } & \multicolumn{2}{|c|}{ Oct } & \multicolumn{2}{|c|}{ Nov } & \multicolumn{2}{|c|}{ Dec } & \multicolumn{2}{|c|}{ Feb } & \multicolumn{2}{|c|}{ Mar } & \multicolumn{2}{|c|}{ Apr } & \multicolumn{2}{|c|}{ May } & \multicolumn{2}{|c|}{ Jun } & \multicolumn{2}{|c|}{ Jul } & \multicolumn{2}{|c|}{ Aug } & \multicolumn{2}{|c|}{ Sept } \\
\hline & & $\mathbf{Z}$ & L.S. & $\mathbf{Z}$ & L.S. & $\mathbf{Z}$ & L.S. & $\mathbf{Z}$ & L.S. & $\mathbf{Z}$ & L.S. & $\mathbf{Z}$ & L.S. & $\mathbf{Z}$ & L.S. & $\mathbf{Z}$ & L.S. & $\mathbf{Z}$ & L.S. & $\mathbf{Z}$ & L.S. & $\mathbf{Z}$ & L.S. \\
\hline \multirow{3}{*}{ Knezha } & $0-20 \mathrm{~cm}$ & & & -2.4 & $*$ & -1.7 & + & -5.25 & $* * *$ & -5.1 & $* * *$ & -2.8 & $* *$ & -2.3 & $*$ & -2.2 & $*$ & -1.3 & & -0.7 & & -1.5 & \\
\hline & $0-50 \mathrm{~cm}$ & & & -1.9 & + & -2.0 & $*$ & -4.56 & $* * *$ & -5.2 & $* * *$ & -3.3 & $* * *$ & -2.4 & $*$ & -2.2 & $*$ & -1.2 & & -0.8 & & -1.7 & + \\
\hline & $0-100 \mathrm{~cm}$ & & & -1.4 & & -1.3 & & -2.89 & $* *$ & -3.5 & $* * *$ & -2.7 & $* *$ & -2.4 & $*$ & -2.0 & $*$ & -1.3 & & -0.9 & & -1.9 & + \\
\hline \multirow{3}{*}{ Novachene } & $0-20 \mathrm{~cm}$ & -0.6 & & -2.4 & $*$ & -3.4 & $* * *$ & -2.5 & $*$ & -4.0 & $* * *$ & -0.9 & & -0.5 & & 0.1 & & -1.1 & & 0.0 & & -0.7 & \\
\hline & $0-50 \mathrm{~cm}$ & -0.5 & & -1.9 & + & -3.0 & $* *$ & -2.2 & $*$ & -3.3 & $* * *$ & -1.5 & & -1.2 & & -1 & & -1.0 & & -0.7 & & -1.7 & + \\
\hline & $0-100 \mathrm{~cm}$ & -0.8 & & -1.7 & + & -2.6 & $* *$ & -2.6 & $* *$ & -3.5 & $* * *$ & -2.7 & $* *$ & -2.5 & $*$ & -2 & + & -1.9 & + & -2.2 & $*$ & -2.9 & $* *$ \\
\hline \multirow{3}{*}{ Pavlikeni } & $0-20 \mathrm{~cm}$ & 0.0 & & -1.7 & + & -1.2 & & & & -3.2 & $* *$ & -1.3 & & 0.6 & & -2.4 & $*$ & -2.0 & $*$ & -3.0 & ** & -1.4 & \\
\hline & $0-50 \mathrm{~cm}$ & 0.9 & & -0.9 & & -0.7 & & & & -3.1 & ** & -1.1 & & 0.4 & & -2.0 & $*$ & -1.5 & & -2.7 & $* *$ & -0.8 & \\
\hline & $0-100 \mathrm{~cm}$ & 1.6 & & 0.2 & & 0.5 & & & & -1.4 & & -0.9 & & 0.2 & & -1.8 & + & -0.9 & & -2.1 & $*$ & -0.2 & \\
\hline \multirow{3}{*}{ Karnobat } & $0-20 \mathrm{~cm}$ & 2.7 & $* *$ & 1.0 & & 1.9 & + & 1.9 & + & 1.4 & & & & & & & & & & & & & \\
\hline & $0-50 \mathrm{~cm}$ & 2.4 & $*$ & 0.5 & & 2.9 & $* *$ & 3.1 & $* *$ & 2.3 & $*$ & & & & & & & & & & & & \\
\hline & $0-100 \mathrm{~cm}$ & 1.9 & + & 0.1 & & 1.1 & & 2.2 & $*$ & 1.9 & + & & & & & & & & & & & & \\
\hline \multirow{3}{*}{ Chirpan } & $0-20 \mathrm{~cm}$ & -0.5 & & -2.3 & $*$ & -2.1 & $*$ & -2.8 & $* *$ & -3.7 & $* * *$ & -2.1 & $*$ & & & -2.7 & $* *$ & & & -1.3 & & & \\
\hline & $0-50 \mathrm{~cm}$ & -1.8 & + & -2.9 & ** & -2.4 & $*$ & -3.1 & $* *$ & -3.3 & $* *$ & -3.0 & $* *$ & & & -3.3 & $* * *$ & & & -2.2 & $*$ & & \\
\hline & $0-100 \mathrm{~cm}$ & -2.3 & $*$ & -3.3 & $* * *$ & -2.4 & $*$ & -2.9 & $* *$ & -2.6 & $*$ & -2.6 & $* *$ & & & -3.1 & $* *$ & & & -2.7 & $* *$ & & \\
\hline
\end{tabular}

Table 5. Normal approximation (Z) and level of significance (L.S.) of rainfall during the period 1951-2010

\begin{tabular}{|c|c|c|c|c|c|c|c|c|c|c|c|c|c|c|c|c|c|c|c|c|c|c|c|c|}
\hline \multirow{2}{*}{ Station } & \multicolumn{2}{|c|}{ Oct } & \multicolumn{2}{|c|}{ Nov } & \multicolumn{2}{|c|}{ Dec } & \multicolumn{2}{|c|}{ Jan } & \multicolumn{2}{|c|}{ Feb } & \multicolumn{2}{|c|}{ Mar } & \multicolumn{2}{|c|}{ Apr } & \multicolumn{2}{|c|}{ May } & \multicolumn{2}{|c|}{ Jun } & \multicolumn{2}{|c|}{ Jul } & \multicolumn{2}{|c|}{ Aug } & \multicolumn{2}{|c|}{ Sep } \\
\hline & $\mathbf{Z}$ & L.S. & $\mathbf{Z}$ & L.S. & $\mathbf{Z}$ & L.S. & $\mathbf{Z}$ & L.S. & $\mathbf{Z}$ & L.S. & $\mathbf{Z}$ & L.S. & $\mathbf{Z}$ & L.S. & $\mathbf{Z}$ & L.S. & $\mathbf{Z}$ & L.S. & $\mathbf{Z}$ & L.S. & $\mathbf{Z}$ & L.S. & $\mathbf{Z}$ & L.S. \\
\hline Knezha & 0.0 & & -1.8 & + & 0.6 & & 0.0 & & -1.1 & & 0.2 & & 0.0 & & -1.5 & & -1.8 & + & -0.2 & & 0.1 & & 1.5 & \\
\hline Novachene & 0.8 & & -1.4 & & 0.5 & & 0.1 & & -0.3 & & 0.2 & & -0.7 & & -1.1 & & -1.3 & & -0.7 & & 1.8 & + & 0.8 & \\
\hline Pavlikeni & -0.1 & & -1.9 & + & -0.6 & & -1.5 & & -0.6 & & -0.8 & & -1.3 & & -0.4 & & -2.7 & $* *$ & -0.2 & & -0.8 & & 1.6 & \\
\hline General Toshevo & 0.0 & & -0.6 & & 0.6 & & 0.5 & & -0.7 & & 1.6 & & -0.3 & & -0.6 & & -1.3 & & 1.4 & & -0.1 & & 2.6 & $*$ \\
\hline Karnobat & 1.09 & & -1.2 & & 0.2 & & -1 & & -1.1 & & 0.9 & & -2 & $*$ & -2.2 & $*$ & -1.5 & & 0.82 & & 0.1 & & 1 & \\
\hline Chirpan & -1 & & -2.6 & $* *$ & 0.4 & & -1.1 & & -1.4 & & -0 & & -1 & & -2.7 & $* *$ & -2.8 & $* *$ & -0.2 & & -0.3 & & 1.6 & \\
\hline
\end{tabular}




\section{Conclusions}

Results of the conducted investigation and comparative analysis relating to soil moisture in different layers, active temperature totals and certain hydrothermal indices can sustain conclusions as follows:

1. Reduced soil water content in the $0-20,0-50$ and $0-100 \mathrm{~cm}$ soil layers was established for the 1981-2010 period as compared with the (1951-1980) reference period, in the cases of the Knezha, Novachene and Chirpan stations, while there was an increase at Tsarev Brod; and a variety of trends in the case of the General Toshevo, Pavlikeni and Karnobat stations.

2. During the period of investigation was observed increase of active temperatures sums for all months of vegetative season between $10-20$ up to $30-35^{\circ} \mathrm{C}$ every month, as biggest as values are in months July and August;

3. No statistically significant differences in soil-water content are noted for Tsarev Brod, General Toshevo or Karnobat. Larger differences achieving significance are the negative ones characterising the remaining stations in winter, with these experiencing shortages of soil water at the beginning of the spring vegetation period.

4. Although there is a decrease in values for the De Martone Index during the vegetation period at most of the stations, values do not go beyond the threshold for the Dry Sub-humid zone. The exception is July in the case of Novachene, Karnobat and Chirpan, as well as August in the case of all stations. Even this period is not vegetative for winter wheat, as conditions associated with a with depletion in soil water content coincide with preparation for the next sowing;

5. Statistically significant downward trends were observed in Knezha, Novachene, Pavlikeni, Karnobat and Chirpan, in the case of the 1951-2010 period overall. The most significant downward trends are those characterizing winter. Soil water content decreases in April at the Kneja and Chirpan stations, as well as in May only at Knezha;

6. The significant decreases in monthly precipitation totals are of lesser magnitude than those relating to soil water supply (Chirpan - November, May and June; Karnobat - April and May; Pavlikeni - June). An upward trend for precipitation totals was observed at General Toshevo in the case of September;

7. Deteriorating conditions as regards humidity were observed during the autumn vegetation period for winter wheat in Knezha and Chirpan. The same tendencies were observed during spring vegetation for Knezha (in April and May) and for Chirpan (in April).

8. The trends for reduced soil water content for the 1951-2010 period achieving the greatest level of significance (0.001) characterized the beginning of spring vegetation: in February in Knezha in the case of the $0-20 \mathrm{~cm}$ and $1-50 \mathrm{~cm}$ layers, and in March at the Knezha and Novachene stations in all soil layers, and in Chirpan in the $0-20 \mathrm{~cm}$ layer. The same trends were observed during the winter in Novachene (at 0-20 cm) and in Chirpan (at 0-100 cm), and during spring vegetation in Knezha and Chirpan $(0-50 \mathrm{~cm})$.

9. Statistically significant trends for a decline in monthly rainfall over the period 1951-2010 (at a significance level of 0.01) relate to Chirpan in November, May and June, and Pavlikeni in June. 


\section{References}

Alexandrov V., 2006. Climate variability and change and related impacts on ecosystems in southeast and central Europe as well as southeast USA. St. Petersburg: Doctoral thesis, Main Geophysical Observatory, $190 \mathrm{pp}$.

Alexandrov V., Radeva S., Koleva E., 2011. Utilization of SPI, PDSI, and RDI as drought indicators in South Bulgaria. 11 th International Multidisciplinary Geoconference Proceedings 2, pp. 969-976.

Bocheva L., 2012. Seasonal variation of heavy precipitation events and distribution of stormy days in Bulgaria (1991-2010). BALWOIS, Ohrid: 28 May-2 June 2012, Republic of Macedonia (ISBN 978-608-4510-10-9).

Bocheva L., Gospodinov I., Simeonov P., Marinova T., 2013. Wide-spread severe convective storm events in Bulgaria (1991-2010), $7^{\text {th }}$ European Conference of Severe Storms ( $7^{\text {th }}$ ECSS), 3-7 June 2013, Helsinki, Finland, http://www.essl.org/ECSS/2013/programme/ [10 October 2015].

Dilkov D., 1959. Soil water probability and regime at chernozems in Bulgaria during the spring. Sofia: Proceedings of Institute of Hydrology and Meteorology, vol. 2, pp. 3-43.

Dilkov D., 1960. Evapotranspiration and water supply of winter wheat in our country. Sofia: Proceedings of Institute of Hydrology and Meteorology, vol. 8, pp. 3-48.

De Martonne E., 1925. Aréisme et indice artidite. Compte Rendu de L'Acad. Sci., Paris, vol. 182, pp. 1395-1398.

Dukov D., 1976. Soil water regime of grey soils and soil water probability of winter wheat, maize and alfalfa. Sofia: Hydrology and Meteorology, vol. 3, pp. 23-33.

Eitzinger J., Thaler S., Orlandini S., Nejedlik P., Kazandjiev V., Vucetic V., Sivertsen T.H., Mihailovic D.T., Lalic B., Tsiros E., Dalezios N.R., Susnik A., Christian K.C. Kersebaum, Holden N.M., Matthews R., 2008. Agroclimatic indices and simulation models. [in:] P. Nejedlik, S. Orlandini (eds.), A survey of agrometeorological practices and aapplications in Europe, regarding climate change impacts. European Science Foundation, COST 734, pp. 15-114.

Georgieva V., 2014. Investigation of the soil water availability on the main soil types for winter wheat growing in Bulgaria. Sofia: PhD Thesis, NIMH, 175 pp.

Georgieva V., Kazandjiev V., Moteva M., 2010. Soil moisture regime of chernozems in Bulgaria and the water supply of winter wheat crops. Proceedings of $2^{\text {nd }}$ International Geography Symposium GEOMED 2010, Antalya, Kemer, Turkey, pp. 53-63.

Georgieva V., Moteva M., Kazandjiev V., 2007. Impact of climate change on water supply probability of winter wheat in Bulgaria. Agriculturae Conspectus Scientificus Journal, vol. 72, no. 1, pp. 39-44.

Georgieva V., Moteva M., Kazandjiev V., 2009. Contemporary water supply of winter wheat in southern Bulgaria. Proceedings XXXIII CIOSTA,CIGRV, 17-19 June 2009, Reggio Calabria, Italy, pp. 1265-1270.

Kazandjiev V., 2008a. Climate change, agroclimatic resources and the determination of unfavourable regions in Bulgaria. [in:] V. Tarnovo, The future development of agriculture in Bulgaria, Sirius, pp. 139-154.

Kazandjiev V., 2008b. Unfavourable regions in Bulgaria determination by the climatic indicators and agroclimatic resources during the period of 1971-2000. Expert report for Ministry of Agriculture and Food (MAF), 50 pp. 
Kazandjiev V., Georgieva V., Joleva D., Tsenov N., Roumenina E., Filchev L., Dimitrov P., Jelev G., 2011. Climate variability and change and conditions for winter wheat production in north-west Bulgaria, Field Crop Studies, vol. 7, no. 2, pp. 195-220 [in Bulgarian].

Kazandjiev V., Georgieva V., Moteva M., 2008. Agroclimatic resources in Bulgaria for field crop cultivation under irrigated and rain-fed conditions. International Conference on Water Observation and Information System for Decision Support, 27-31 May, Ohrid, Macedonia, CD version

Kazandjiev V., Georgieva V., Moteva M., 2009. Climate change, agroclimatic resources and agroclimatic zoning of agriculture in Bulgaria. 9-th EMS/ECAM Conference, Toulouse, France.

Kazadjiev V., Moteva M., Georgieva V., 2014. Near and far future climate conditions for crop growing in Bulgaria. Proceedings $12^{\text {th }}$ International Congress on Mechanization and Energy in Agriculture, 3-6 September, Cappadokia, Turkey, pp. 183-189.

Koleva E., Alexandrov V., 2008. Drought in the Bulgarian low regions during the $20^{\text {th }}$ century. Theoretical and Applied Climatology, vol. 92, pp. 113-120.

Slavov N., Georgieva V., 2005. The effect of climate change upon perennial fluctuations of the soil water content in south Bulgaria. Proceedings on Breeding and Cultural Practices of the Crops, pp. 363-368.

Slavov N., Moteva M., Georgieva V., 2005. The climate change during the last century in northeaster Bulgaria and related impact on agriculture. Proceedings of the Union of Scientists, Rousse, Agricultural and Veterinary Sciences, vol. 3, pp. 160-165.

Stanev S., Kuchukova M., Lingova S. (eds.), 1991. The climate of Bulgaria. Sofia: Publishing House of the Bulgarian Academy of Sciences, 498 pp.

Vandova M., Serkedjieva I., 1984. Statistical structure of field of soil water content at chernozems in north Bulgaria. Proceedings of Agricultural Meteorology, II, pp. 77-88.

Vangelov A., 1963. Autumn-winter accumulation of water in cinnamonic forest soils in our country. Sofia: Hydrology and Meteorology, vol. 4, pp. 39-49.

Vangelov A., 1965. About the moisture regime of the cinnamonic forest soils in Bulgaria. Sofia: Proceedings of Institute of Hydrology and Meteorology, vol. 4, pp. 95-130.

WMO, 2012. Statement on the Status of the Global Climate in 2012. World Meteorological Organization No. 118. 